\title{
Populationsutveckling hos svarthakad buskskvätta Saxicola rubicola under expansionens inledningsskede i Västsverige
}

\author{
Population development of European Stonechat \\ Saxicola rubicola during the initial phase \\ of its expansion in Western Sweden
}

Reino Andersson

Rödaledstigen 6, 43253 Varberg, Sweden | samreinoandersson@gmail.com

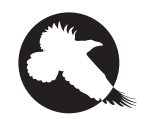

WITH ITS 25 confirmed breeding records between 2000 and 2015, the European Stonechat Saxicola rubicola is historically a rare bird in Sweden. The first breeding in the West Coast was found in 2014. Censuses performed in 2017 and 2018 revealed 28 and 30 breedings respectively. Out of 83 investigated territories, most were found in coastal heathlands in Halland. The arrival occurred in the turn of the months March/April and the majority of the males consisted of one year old birds (2CY). Fledgling date for 68 clutches were distributed from May to August. Second clutches were observed for ten out of 32 investigated breedings. The Swedish expansion should be seen in the context of Danish immigration in combination with a large-scale advance via the German Schleswig-Holstein area. The European Stonechat belongs to those range-expanding species that are expected to increase according to predictions of the future bird fauna. Due to warmer climate, plenty of appropriate habitats and high probability of reproduction, the conditions are good for a continued range expansion in southern Sweden.

Keywords: range expansion | breeding | climate change | habitat | passerine bird

\section{Introduktion}

Svarthakad buskskvätta Saxicola rubicola är historiskt en sällsynt fågel i Sverige och så sent som 1961 förelåg endast 15 fynd (Rudebeck 1962, SOF 1965). På svenska

Västkusten uppgick antalet till elva fynd i början av 1980-talet, sex av dem i Göteborg/Bohuslän och fem i Halland (Wirdheim \& Carlén 1986, Åhlund 2007, Björk- 
man m. fl. 2009). Det första exemplaret utgjordes av ett skjutet exemplar strax söder om Göteborg 1902 (Bothen 1902). Senare under 1980 - och 1990-talen inrapporterades ett fătal individer årligen på Västkusten (SOF 2002).

År 2000 påträffades den första häckningen i Sverige nära Simrishamn i Skåne (Bengtsson 2000). Två år tidigare hade dock samhäckning med en hona av vanlig buskskvätta Saxicola rubetra ägt rum i Västergötland (SOF 2002). Fram till och med 2015 konstaterades 25 häckningar i landet. Utanför Skåne där de flesta paren återfanns, genomfördes en häckning i Västergötland 2004, en i Halland 2014 och tre i samma landskap 2015. Under våren 2016 uppträdde svarthakade buskskvättor $i$ en aldrig tidigare skådad omfattning. Rekorduppträdandet resulterade i totalt 34 svenska häckningar, fördelat på ett par i Västergötland, två i Bohuslän, 13 i Halland och 18 i Skåne (Dahlén \& Söderquist 2016, Wernersson 2017).

I Danmark har utvecklingen varit likartad med ett första häckfynd 1942 och ett fåtal oregelbundna fynd under påföljande decennier. Ännu i början av 1970-talet påträffades några få häckande par, men i början av 1990-talet skedde en markant ökning. Några egentliga inventeringar har inte genomförts, men vid en uppskattning 2012 översteg antalet revir 300. Från att ha varit bunden till hedbiotoper utmed Jyllands västkust, har den i takt med expansionen vidgat sitt biotopval och spridit sig även till inlandet (Dybbro 1976, Nyegaard m.fl. 2014).

Under 1970-talet etablerades även ett bestånd längs Norges sydvästkust, vilket anses härstamma från de brittiska öarna. Numerären har varierat med som mest 50-100 par, medan arten vissa perioder har varit försvunnen, främst beroende på effekten av kalla vintrar (Størkersen 1994, Shimmings \& Öjen 2015).

Denna uppsats avser att dokumentera expansionens förlopp under häckningstid (mars-augusti) på Västkusten (Göteborg/Bohuslän, Halland) under den senaste tioårsperioden (2009-2018). Särskilt fokus riktas dock på häckningssäsongerna 2017 och 2018, då systematiska inventeringar genomfördes i varierande omfattning. Uppsatsen kan förhoppningsvis ligga till grund för framtida uppföljningar av artens populationsutveckling.

\section{Material och metoder}

Historiska publicerade uppgifter har genomsökts spe- cifikt för Västkusten, men också för Skandinavien som helhet, för att få en samlad bild av expansionens förlopp. Materialet för Västkusten som redovisas i uppsatsen, grundar sig i stor utsträckning på spontana rapporter som inkommit till databasen Artportalen (Artportalen 2018). Eftersom svarthakad buskskvätta tillhört en av landets ovanligare arter, kan man förmoda att rapporteringsfrekvensen varit hög. Under det första rekordåret 2016 tilldrog sig arten ett större intresse än tidigare med fler besök på tänkbara lokaler, vilket resulterade i en mer detaljerad bild av häckningsförekomsten.

Det var dock först 2017 som eftersökningarna utöver den spontana rapporteringen skedde systematiskt. Då genomfördes regelbundna och riktade besök under häckningstid utmed kustbandet i mellersta Halland. Delar av Väröhalvön, Getterön och sträckan Rosendal till Morups tånge genomsöktes praktiskt taget dagligen. I de övriga lämpliga kustområdena kvantifierades inte besöken på samma sätt. I landskapets södra och norra delar samt i Göteborg/Bohuslän var fynden av mer spontan karaktär. I inlandet uteblev dock kontroller nästan helt.

Häckningssäsongen 2018 bedrevs utöver den spontana rapporteringen systematiska inventeringar utmed hela Västkusten. Dessa hade föregåtts av flera artiklar och upprop i bland annat tidskrifterna Vår Fågelvärld och Fåglar på Västkusten (Andersson 2017, 2018). Dessutom hade ett antal initierade ornitologer vidtalats på förhand. Hallands kustområden blev därmed relativt väl undersökta, med undantag av dess sydligaste del i Laholms kommun. Lämpliga delar av Kungsbacka kommun, Väröhalvön, Varbergstrakten och sträckan Rosendal till Morups tånge kontrollerades så gott som dagligen. Utmed den övriga kuststräckan i mellersta Halland gjordes minst ett besök per vecka. Även kustnära områden i Göteborg/Bohuslän genomsöktes, bland annat i samband med strandängsinventeringar utförda i annat syfte. Även inlandet i Halland täcktes av inventeringarna, men i varierande grad. Exempelvis blev lämpliga inlandslokaler i Kungsbacka och Varbergs kommuner besökta minst en gång per månad. Däremot uteblev kontrollerna i Halmstad och Laholms kommuner. Vissa delar av Falkenbergs inland besöktes sporadiskt.

Fynden av adulta individer delas upp i tillfälliga observationer, permanenta sångrevir, troliga och säkerställda häckningar. Med en tillfällig observation menas 
att fåglar uppehållit sig maximalt några dagar på en lokal, medan ett sångrevir bedömts som permanent om en hanne tillbringat minst tio dagar på platsen, varav merparten efter den 15 april. Klassningen av häckningsstatus följer de kriterier för trolig (kategori 5-10) respektive säkerställd häckning (kategori 11-20) som anges i Svensk Fågelatlas (Svensson m. fl. 1999).

Försök till en grov klassning av biotoperna gjordes för samtliga revir 2014-2018, vilket resulterade i fem olika biotoptyper. Drygt hälften av alla hannar hade dokumenterats med tillräckligt detaljerade foton för att en åldersbestämning skulle kunna ske. Åldersbestämningen har gjorts av författaren med utgångspunkt från allmänna ruggningskriterier (Svensson 1992, Hellström \& Waern 2005, Hellström \& Waern 2011). Några av de viktigaste karaktärerna var eventuell förekomst av ruggningsgräns bland större täckarna, det relativa slitaget och utseendet hos handtäckare och handpennor. Även ankomst- och flyggdatum har registrerats i samband med inventeringarna. Uppgifterna om ankomst baseras enbart på de revir som stått under regelbunden uppsikt. Flyggdatum har fastställts utifrån de utflugna ungarnas fjäderdräkt och beteende.

\section{Resultat}

\section{PERIODEN 2009-2016}

Under åren 2009-2013 rapporterades mellan fem och tio vårfynd årligen, samtliga av kortvarig karaktär. Lik-

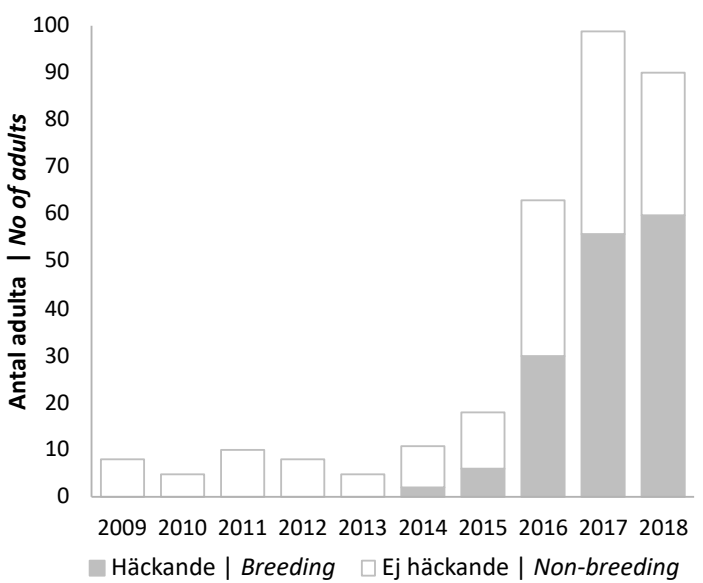

FIGUR 1. Antal adulta individer under häckningsperioden 2009-2018, fördelat på häckande och ej häckande.

- Number of adult individuals during the breeding season 2009-2018 specified to breeding and non-breeding birds.

nande numerär uppvisades 2014, då Västkustens första häckning registrerades vid Lya ljunghed i södra Halland. Under 2015 iakttogs 18 individer, därav ett häckande par vardera vid Mästocka ljunghed, Stensjöstrand och Klosterfjorden. En dramatisk uppgång av antalet fynd skedde 2016 med 63 individer, därav tre permanenta sångrevir, en trolig och 14 säkerställda häckningar. Två av dessa upptäcktes vid Mollön och Kalvöfjorden i Bohuslän, medan 13 häckningar var koncentrerade främst till södra och mellersta Halland (tabell 1, figur 1).

TABELL 1. Observerad närvaro på samtliga 83 revir 2014-2018. P (permanent sångrevir), T (trolig häckning), S (säkerställd häckning). - Observed presence in all 83 territories in 2014-2018. P (permanent song territory), T (possible breeding), S (confirmed breeding).

\begin{tabular}{|c|c|c|c|c|c|c|}
\hline $\begin{array}{l}\text { Kommun } \\
\text { Municipality }\end{array}$ & $\begin{array}{l}\text { Lokal } \\
\text { Site }\end{array}$ & 2014 & 2015 & 2016 & 2017 & 2018 \\
\hline Uddevalla & Mollön & & & $\mathrm{S}$ & & \\
\hline Orust & Kalvöfjorden & & & $\mathrm{S}$ & & \\
\hline \multirow[t]{2}{*}{ Kungälv } & Oxhagen & & & & $S$ & \\
\hline & Toreby & & & & & $\mathrm{S}$ \\
\hline Mölndal & Fässberg & & & & $\mathrm{S}$ & \\
\hline \multirow[t]{5}{*}{ Kungsbacka } & Vallda Sandö & & & & & $\mathrm{S}$ \\
\hline & Prästbron & & & $\mathrm{S}$ & $\mathrm{T}$ & $S$ \\
\hline & Riddarekulle & & & $\mathrm{P}$ & $S$ & $S$ \\
\hline & Sandbäck & & & & & $P$ \\
\hline & Hönsaryd & & & & & $\mathrm{S}$ \\
\hline
\end{tabular}


TABELL 1 fortsatt | Table 1 continued.

\begin{tabular}{|c|c|c|c|c|c|c|}
\hline $\begin{array}{l}\text { Kommun } \\
\text { Municipality }\end{array}$ & $\begin{array}{l}\text { Lokal } \\
\text { Site }\end{array}$ & 2014 & 2015 & 2016 & 2017 & 2018 \\
\hline & Svinholmen & & & & $T$ & \\
\hline & Deberg & & & & $\mathrm{T}$ & S \\
\hline & Skällträ & & & & S & S \\
\hline & Rågelund & & & & & S \\
\hline & Frillesås N & & & & & S \\
\hline & Frillesås S & & & & & $\mathrm{T}$ \\
\hline \multirow[t]{15}{*}{ Varberg } & Kärra N & & & S & & S \\
\hline & Kärra S & & & & & S \\
\hline & Båtafjorden N & & & & & S \\
\hline & Båtafjorden S & & & & & S \\
\hline & Båtafjordens tornparkering & & & & S & S \\
\hline & Båtafjordens fågeltorn & & & & $\mathrm{s}$ & S \\
\hline & Båtafjorden Attestorp & & & & s & S \\
\hline & Båtafjorden Båle & & & & & S \\
\hline & Bua strand & & & & s & \\
\hline & Klosterfjorden $\mathrm{N}$ & & & & S & S \\
\hline & Klosterfjorden M & & & & & S \\
\hline & Klosterfjorden S & & S & S & S & S \\
\hline & Uddarna Fyrstrandsfjorden & & & & & $\mathrm{T}$ \\
\hline & Getteröns naturreservat & & & & S & \\
\hline & Sik strandängar & & & & & $\mathrm{T}$ \\
\hline \multirow[t]{12}{*}{ Falkenberg } & Rosendal & & & S & $\mathrm{T}$ & \\
\hline & Digesgård N & & & s & s & \\
\hline & Digesgård S & & & $P$ & $\mathrm{P}$ & \\
\hline & Björnhult & & & & $\mathrm{s}$ & \\
\hline & Lövstaviken $\mathrm{N}$ & & & S & S & S \\
\hline & Lövstaviken S & & & $P$ & $\mathrm{~s}$ & \\
\hline & Skrea & & & & & S \\
\hline & Skreanäs & & & & S & S \\
\hline & Ringsegård & & & S & & $\mathrm{T}$ \\
\hline & Grimsholmen & & & & s & S \\
\hline & Ugglarp & & & & & $P$ \\
\hline & Stensjöstrand & & s & s & s & s \\
\hline \multirow[t]{7}{*}{ Halmstad } & Särdal & & & s & s & s \\
\hline & Haverdal & & & S & $\mathrm{T}$ & \\
\hline & Skälvik & & & S & S & \\
\hline & Ringenäs & & & S & S & \\
\hline & Ringenäs badplats & & & & $\mathrm{T}$ & \\
\hline & Hagön & & & & s & \\
\hline & Mästocka & & S & & & \\
\hline \multirow[t]{2}{*}{ Laholm } & Lagaoset & & & $\mathrm{T}$ & & \\
\hline & Lya ljunghed & S & & & & \\
\hline
\end{tabular}




\section{A}

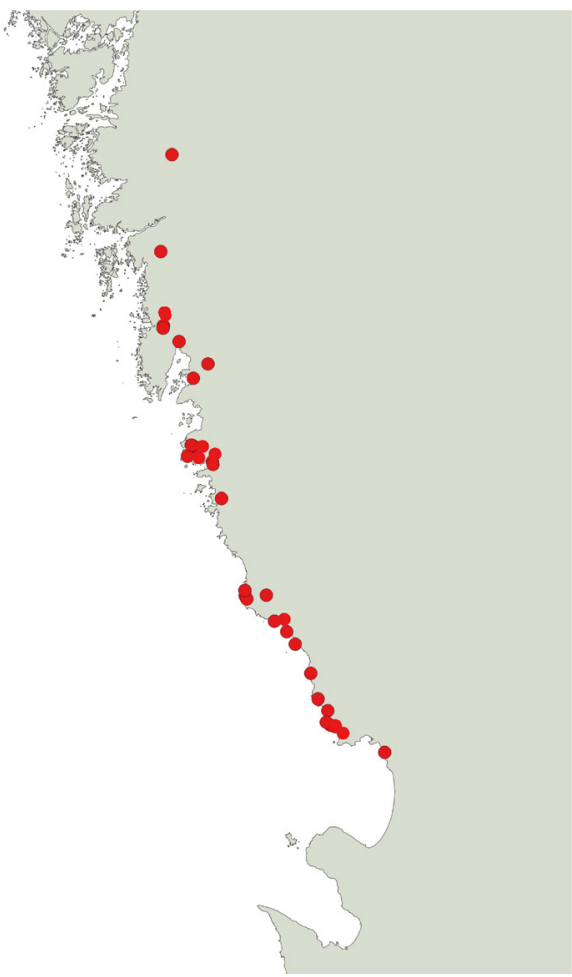

B

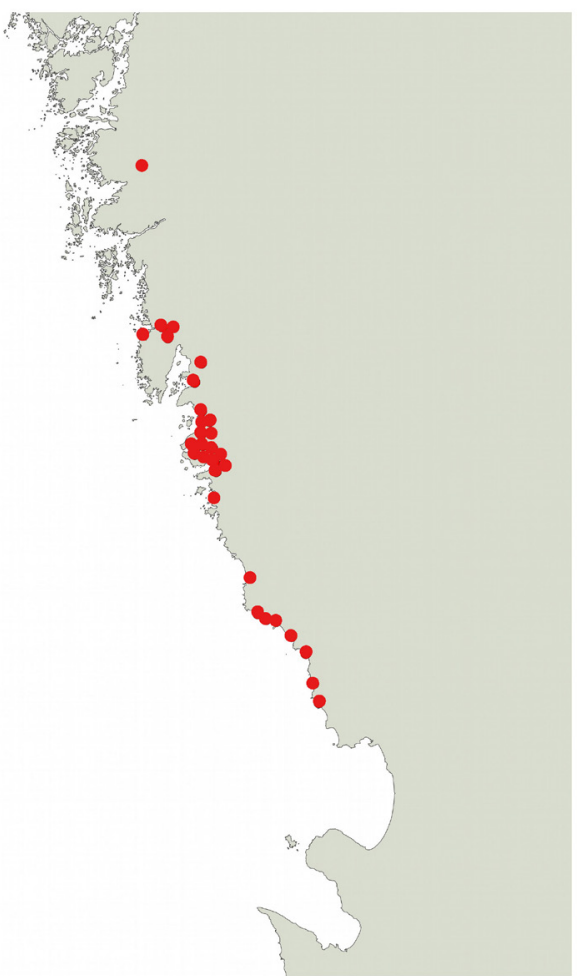

FIGUR 2. Geografisk utbredning av samtliga häckningar: 28 under 2017 (a) och 30 under 2018 (b). Kartan är ett utsnitt av svenska västkusten, från Stenungsund i norr till Höganäs i söder (nordligaste punkten på kustlinjen vid 58 $12^{\prime} \mathrm{N} 11^{\circ} 33^{\prime} \mathrm{E}$ och sydligaste vid $56^{\circ} 18^{\prime} \mathrm{N} 12^{\circ} 56^{\prime} \mathrm{E}$ ). - Geographic distribution of all breedings: 28 in 2017 (a) and 30 in 2018 (b). The map shows a part of the Swedish West Coast from Stenungsund in the north to Höganäs in the south (with the northernmost point of the coastline at $58^{\circ} 12^{\prime} \mathrm{N} 11^{\circ} 33^{\prime} \mathrm{E}$ and the southernmost point at $\left.56^{\circ} 18^{\prime} \mathrm{N} 12^{\circ} 56^{\prime} \mathrm{E}\right)$.

\section{HÄCKNINGSSÄSONGEN 2017}

Under säsongen 2017 observerades 99 individer. Av dem klassades 42 som tillfälliga observationer. Därutöver noterades ett permanent sångrevir, medan resterande 56 individer (28 par) uppvisade kriterier för trolig (6) eller säkerställd (22) häckning. Två av dessa påträffades vid Oxhagen, Kungälv och Fässberg, Mölndal, medan resten fanns i halländska kustområden. Koncentrationen var liksom tidigare stor utmed kuststräckan Falkenberg-Halmstad, men även Varberg och Kungsbacka kommuner hyste ett flertal par (tabell 1, figur 1 och figur 2a).

\section{HÄCKNINGSSÄSONGEN 2018}

Inventeringarna 2018 resulterade i en fyndbild lik fjolårets med 90 olika individer, varav 28 klassades som tillfälligt uppträdande. Två av fåglarna ingick i perma- nenta sångrevir, medan 60 (30 par) var troliga (4) eller säkerställda häckningar (26). En av dem låg vid Toreby i södra Bohuslän och resten i Halland. Till skillnad från förra året låg dock tyngdpunkten i norra Halland, med tio revir i Kungsbacka och 13 i Varbergs kommun (tabell 1 , figur 1 och figur $2 b$ ).

\section{REVIRTÄTHET}

Väröhalvön hyste en anmärkningsvärd koncentration av häckningar och uppvisade de högsta revirtätheterna. Enbart i Båtafjorden registrerades fyra respektive sex revir under 2017-2018. Fyra av reviren 2018 låg sida vid sida, medan avståndet till de två andra uppmättes till cirka 450 respektive 900 meter från närmsta revir (figur 3). I Klosterfjorden låg 2018 tre häckrevir vägg i vägg med varandra. Revirstorleken uppgick till cirka tre hektar, inom vilka paren uppehöll sig väldigt stationärt. 


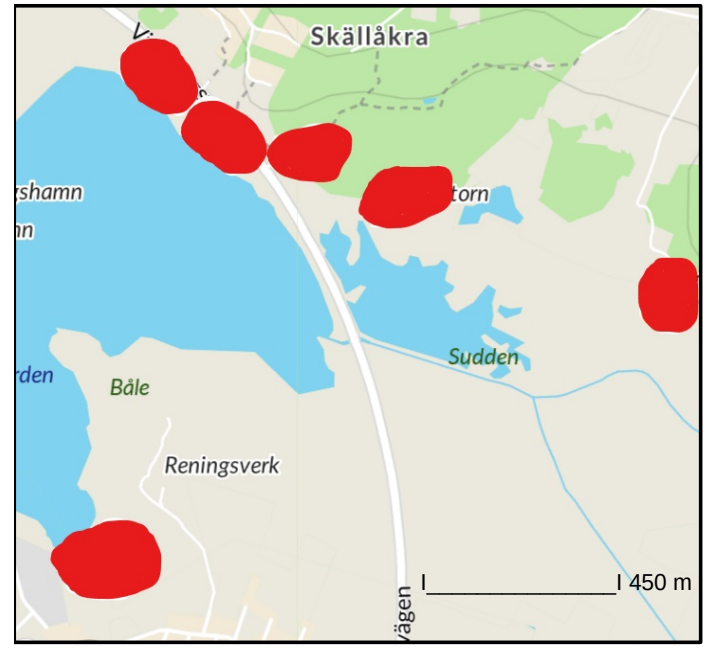

FIGUR 3. Revirtäthet i Båtafjorden 2018.

- Territory density in Båtafjorden 2018.

Den längsta sträcka som någon fågel observerades flyga utanför revirgränsen var cirka 150 meter.

\section{ANKOMST}

Ankomsten på 13 kontrollerade häckrevir 2017 skedde tidigt på våren med majoriteten i mars (medel 23 mars). Tidpunkt för ankomst på 18 kontrollerade revir 2018 inföll i medeltal 13 dagar senare, i första halvan av april

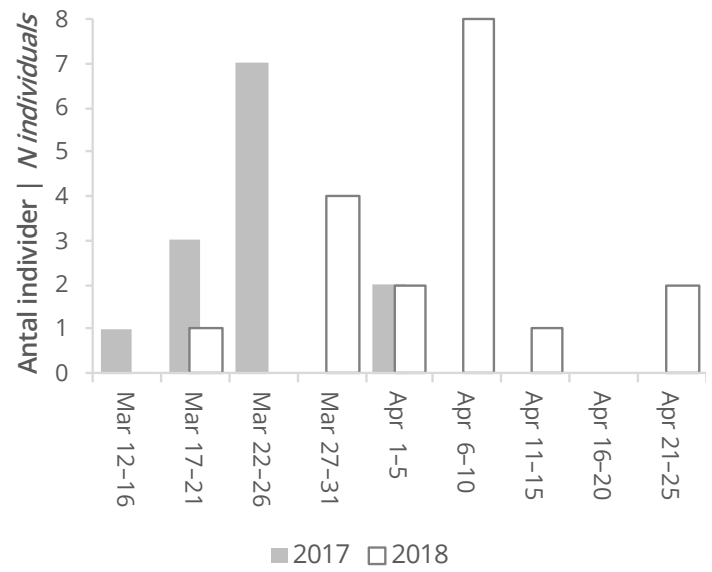

FIGUR 4. Ankomstdatum för 31 kontrollerade revir våren 2017 och 2018, fördelat på femdagarsperioder.

- Arrival date for 31 surveyed territories during the springs of 2017 and 2018, divided into five-day periods. (medel 5 april, figur 4). I 21 av dessa 31 revir (68\%) uppträdde fåglarna parvis redan vid första observationstillfället.

\section{HANNARNAS ÅLDERSFÖRDELNING}

Av totalt 83 revirhannar 2014-2018 fanns tillräckligt detaljerade foton på 42 av dem (51\%). Av dessa utgjordes $32(76 \%)$ av ettåriga hannar $(2 \mathrm{~K})$ medan resterande tio bedömdes som adulta $(3 \mathrm{~K}+)$. Intressant var att på två lokaler som var besatta under tre säsonger i följd uppträdde enbart $2 \mathrm{~K}$-hannar.

\section{BIOTOPER}

Biotoperna var väldigt skiftande och präglades framför allt av kusthedar i södra och mellersta Halland. I norra Halland och Göteborg/Bohuslän var biotopvalet bredare, med förekomst även i fuktstråk med örtvegetation, buskar och smärre vasspartier. Även ruderatmarker som igenväxta soptippar visade sig vara attraktiva. Flera par återfanns dessutom i öppna miljöer med låg vegetation såsom åkrar lagda i träda. Vid en genomgång av biotoperna på samtliga 83 revir erhölls följande fördelning; kusthed 41, fuktstråk 26, åkermark 9, ruderatmark 5, ljunghed 2. Två av reviren, med kusthed respektive ruderatmark, hyste häckningar tre år i följd. Ytterligare två revir var besatta av häckande par fyra år i rad, ett med kusthed och ett med fuktstråk (tabell 1, figur 5-7).

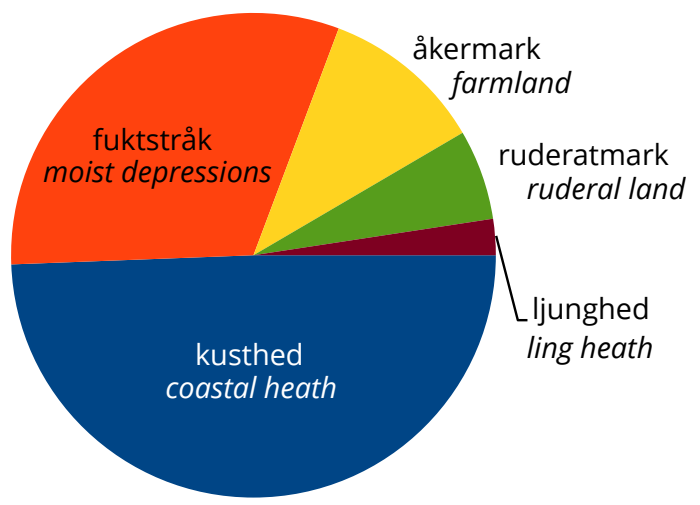

FIGUR 5. Habitatfördelning för samtliga 83 revir 2014-2018. - Habitat distribution for all 83 territories in 2014-2018. 


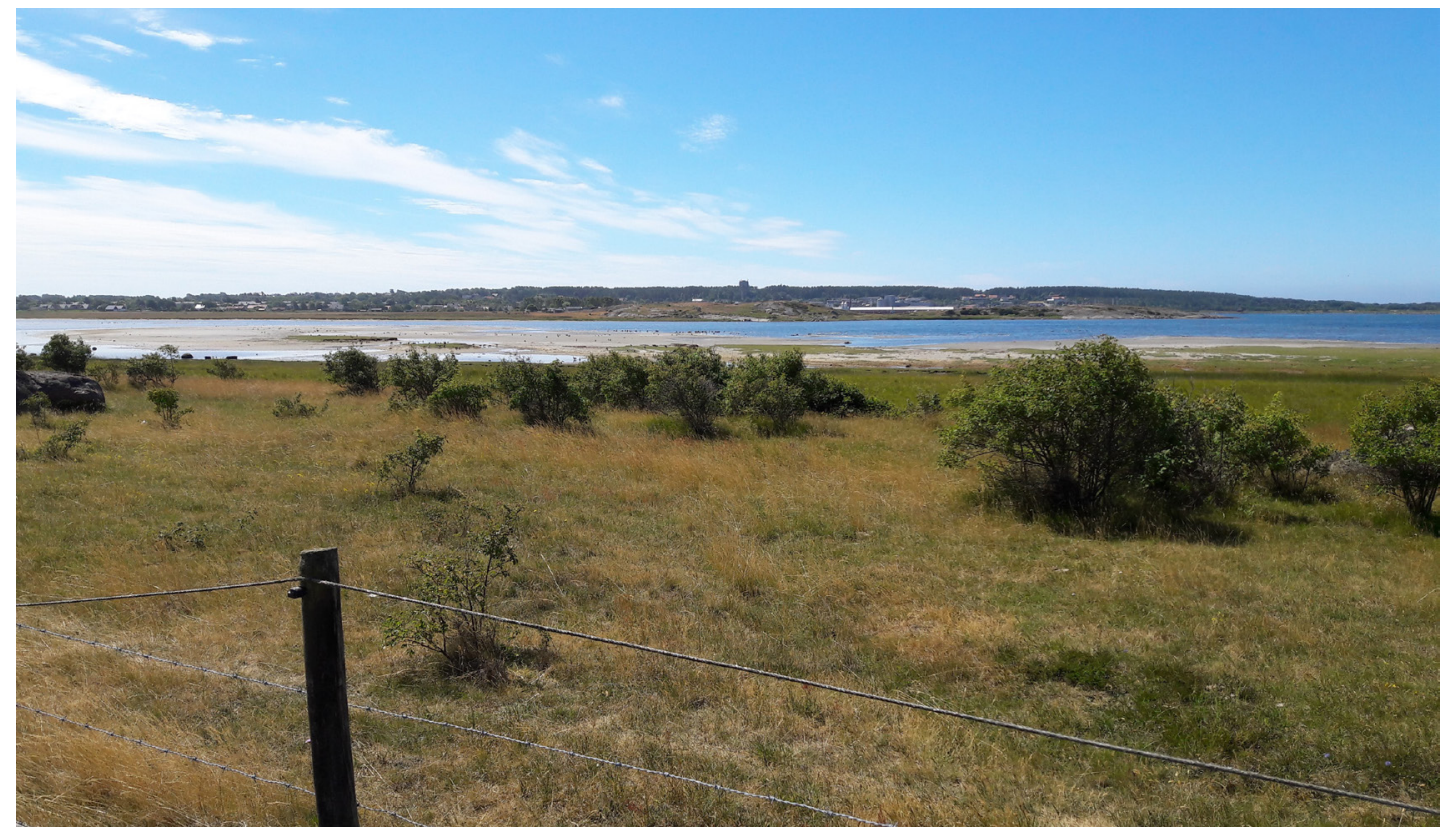

FIGUR 6. Kusthed i Båtafjorden. Foto: Reino Andersson

- Coastal heathland in Båtafjorden. Photo: Reino Andersson

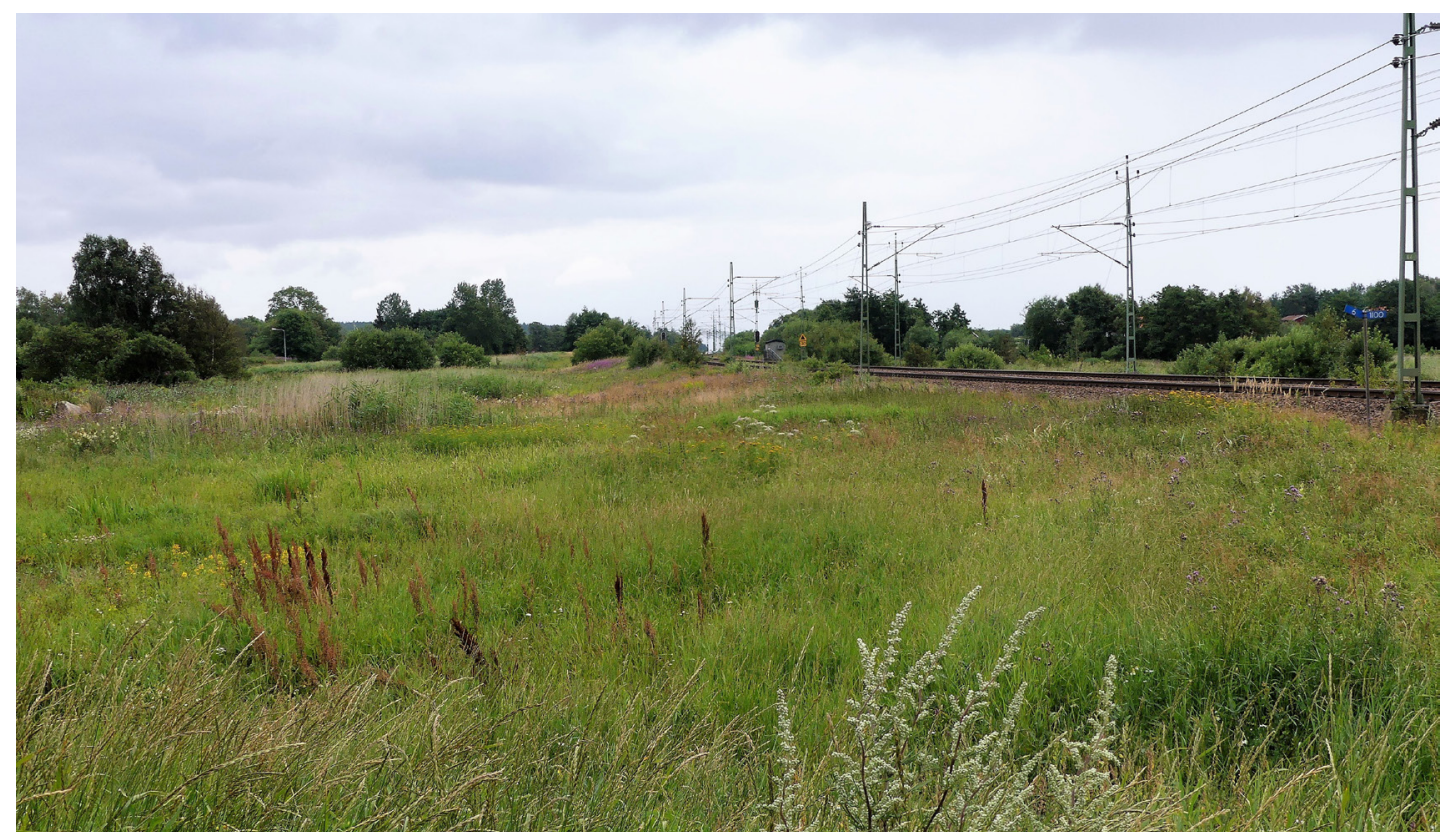

FIGUR 7. Fuktstråk i Klosterfjorden. Foto: Anette Andersson

- Moist depressions in Klosterfjorden. Photo: Anette Andersson 


\section{FLYGGPERIOD}

Flyggdatum för 68 kullar 2014-2018 visade sig vara utspridda över en lång period från maj till augusti, dock med en viss koncentration till månadsskiftena maj/juni, juni/juli och juli/augusti (figur 8). Av de 77 häckningarna 2014-2018 kontrollerades vissa häckningsdata för 32 av dem. Hos tio av dessa (31\%) konstaterades två kullar, en lyckad förstakull med flygga ungar och en lyckad andrakull med utflugna ungar. I dessa siffror ingår alltså inga omläggningar. Däremot kan andrakullarna vara underrepresenterade på grund av att de misslyckats och undgått upptäckt. Tidpunkten då de tio säkra förstakullarna lämnade bona inföll i medeltal 30 maj, medan andrakullarnas medelvärde hamnade på 17 juli. Det föreligger inga säkra indicier för att tredjekullar skulle ha förekommit. Förstakullarnas ungar tenderade efter självständigheten att sprida sig till de närbelägna omgivningarna, medan andrakullarna i högre utsträckning föreföll att stanna kvar på reviren med föräldraparen. Där genomförde de senare ruggningen i de adulta făglarnas närhet.

\section{Diskussion}

Den svarthakade buskskvättans expansion på Västkusten och i andra delar av landet, bör ses mot bakgrund av den danska invandringen och en omfattande framstöt från sydväst via tyska Schleswig-Holstein. Från en oregelbunden förekomst där, med enstaka par fram till 1980-talet, har en omfattande utvidgning av utbred-

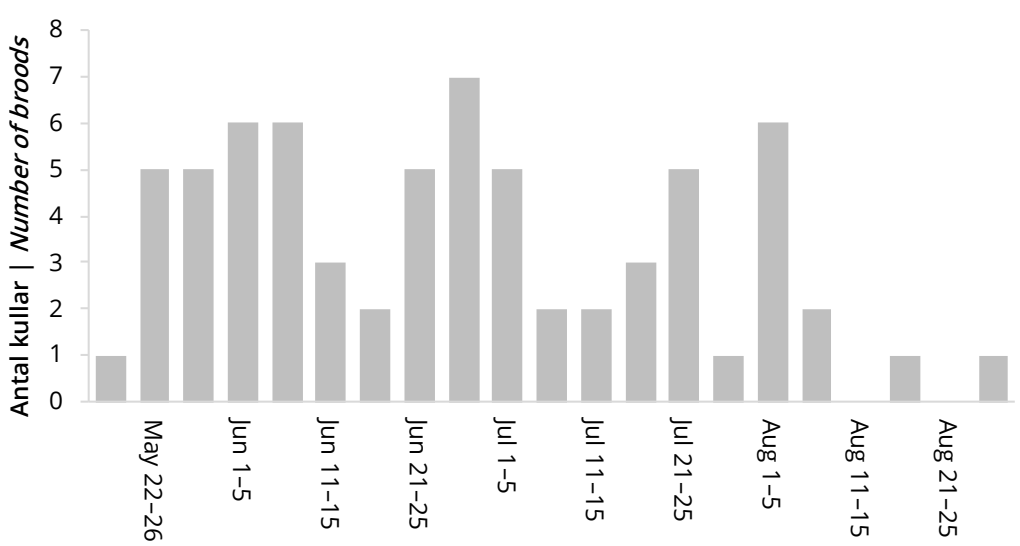

FIGUR 8. Flyggdatum för 68 kullar 2014-2018, fördelat på femdagarsperioder. - Fledging dates for 68 clutches in 2014-2018, divided into five-day periods. ningsområdet ägt rum med numerärer på över 500 par. Därifrån har det skett en spridning mot öster till Mecklenburg-Vorpommern och en liknande utveckling har skett även i andra delar av Tyskland. Schleswig-Holstein uppvisar en betydligt högre populationstäthet än svenska Västkusten. I andra tyska delområden och i Medelhavsområdet uppnås dock avsevärt högre tätheter (Cramp 1988, Eichtstädt m. fl. 2006, Knief m. fl. 2010, Gedeon m. fl. 2014).

En pågående färgmärkningsstudie i Skåne antyder att relativt få fåglar återvänder påföljande säsong (Dahlén \& Söderquist 2015, 2016). Det skulle kunna indikera att den ökning vi nu ser främst beror på en överproduktion i kärnområdena längre söderut. Andelen 2K-hannar på Västkusten var hög jämfört med sydligare populationer, vilket talar för att det sker ett individtillskott till våra häckningsområden (jfr Glutz von Blotzheim \& Bauer 1988). I Norge där svarthakad buskskvätta i huvudsak är en stannfågel, sker efter decimering kalla vintrar en omfattande återinvandring, förmodligen från Storbritannien (Shimmings \& Öjen 2015). Detta förlopp med en påspädning söderifrån främst av yngre fåglar har tidigare kunnat påvisas hos en rad arter som spridit sig norrut, exempelvis svart rödstjärt (Andersson 1987, 2015) och skedstork (Nyegaard m.fl. 2014). Ett annat aktuellt exempel på snabb expansion från sydligare utbredningsområden är vitstjärnig blåhake, vars utveckling är påfallande lik svarthakad buskskvätta. I Danmark har blåhaken sedan 1990-talet etablerat sig med flera hundra revir efter en explosionsartad utveckling i NV Tyskland och Holland (SOVON 2002, Gedeon m. fl. 2014). I sydvästra Sverige handlar det dock ännu så länge bara om sporadiska fynd eller enstaka häckningar (Klinteroth 2015, Artportalen 2018).

Ankomsten i Västsverige sker ungefär två veckor senare jämfört med vissa sydligare populationer (Glutz von Blotzheim \& Bauer 1998). En stor andel av vårobservationerna har utgjorts av tillfälligt uppträdande indi- 
vider, som ofta observerats i kustbandet. Sannolikt handlar det om fåglar som just anlänt och rastar innan de drar vidare. I vilken mån dessa individer senare ingår i det häckande beståndet är ovisst. Att vissa par anlände samtidigt till häckplatserna är intressant, då det noterats i flera studier att upp till $50 \%$ av paren anländer tillsammans (Cramp 1988). Även de tillfälligt uppträdande fåglarna har påfallande ofta noterats parvis. Cramp (1988) spekulerar kring om parbildningen möjligen sker redan på rastplatser under vårflyttningen.

Flyttande populationer i Mellaneuropa lägger regelmässigt två kullar, medan stannfåglar ofta producerar tre och ibland upp till fyra kullar. I några engelska studier lade samtliga studerade par två kullar, $84 \%$ tre och $8 \%$ fyra kullar. Av materialet från Västkusten framgår att endast $31 \%$ av paren lade två kullar och att det saknas indikationer för fler. Även om man kan anta att en del andrakullar missats, blir ändå resultatet betydligt lägre än i sydligare populationer. Däremot förefaller revirstorleken vara i proportion med andra utbredningsområden, liksom parens begränsade rörlighet under häckningstid. Likaså redovisas utomlands att ungarna sprider sig som längst 500-1 00o meter från födelseplatsen, vilket tycks stämma väl överens med våra häckningsområden ( $\mathrm{jfr}$ Cramp 1988, Glutz von Blotzheim \& Bauer 1988).

Den svarthakade buskskvättan tillhör de arter på frammarsch som brukar förknippas med klimatförändringen och förväntas öka enligt prognoser för den framtida fågelfaunan (Huntley m. fl. 2007, Haas m. fl. 2014). Att klimatet har en stor påverkan råder knappast några tvivel om, då populationer på andra håll ofta har uppvisat stora variationer med kraftig nedgång efter kalla vintrar (Glutz von Blotzheim \& Bauer 1988, Shimmings \& Öjen 2015). Det framgår också av den sena ankomsten på Västkusten våren 2018, då det rådde en osedvanligt kall väderlek med kyla långt ned i Mellaneuropa. Detta kan säkert ha inverkat på reviretableringen och lett till färre par än det annars skulle ha varit. Därmed är det rimligt att räkna med tillfälliga bakslag för den svarthakade buskskvättans fortsatta expansion. I takt med ett allt varmare klimat, stor tillgång på lämpliga biotoper och dokumenterat hög reproduktionsförmåga, är dock förutsättningarna goda för en snabb återhämtning och fortsatt spridning i södra Sverige.

\section{Tack}

Tack till Andreas Wernersson, Kåre Ström, Håkan Nilsson och Mats Lundberg för genomläsning av manuskriptet. Tack också till Robin Andersson som har översatt texten till engelska, Anette Andersson som svarat för fotodokumentationen samt Göteborgs Ornitologiska Förening. Värdefulla inventeringsinsatser gjordes av Håkan Nilsson, Gunnar Nyström, Folke Holmqvist, Doris Holmqvist, Kristoffer Nilsson, Matti Åhlund och Ingemar Åhlund. Ett tack riktas också till alla som rapporterat sina observationer på Artportalen. se, vilka till stor del legat till grund för denna uppsats.

\section{Referenser}

Andersson R. 1987. Revirtäthet och populationsstruktur hos ett västsvenskt bestånd av svart rödstjärt Phoenicurus ochruros. Vår Fågelvärld 46: 256-269.

Andersson R. 2015. Andra världskrigets ruinstäder och dess betydelse för svarta rödstjärtens Phoenicurus ochruros expansion i norra Europa. [The Second World War ruined cities and their importance for the expansion of the Black Redstart Phoenicurus ochruros in northern Europe]. Ornis Svecica 25: 45-50. https://doi.org/10.34080/ os.v25.19601

Andersson R. 2017. Svarthakade buskskvättans expansion på Västkusten. Fåglar på Västkusten nr 4: 26-31.

Andersson R. 2018. Svarthakad buskskvätta expanderar i väst. Vår Fågelvärld 77(2): 30-32.

Artportalen, SLU. 2018. Artportalen - rapportsystem för växter, djur och svampar. Available at https://www.artportalen.se, accessed in December 2018.

Bengtsson K. 200o. Ny skånsk häckfågel - svarthakad buskskvätta. Anser 39: 178-179.

Björkman P, Håkansson J, Lydmark P, Molin M, Oomen M, Svanberg S, Svedholm J \& Unger M. 2009. Fågelrapport för Göteborgs rapportområde 2008. Fåglar på Västkusten, supplement 36: 15-24.

Bothen CO. 1902. Nytt fynd av svarthalsade buskskvättan (Saxicola rubicola) i Sverige. Öfversigt af Kongliga Vetenskaps-Akademiens Förhandlingar 59: 65-66.

Cramp S. 1988. The Birds of the Western Palearctic. Oxford University Press, Oxford.

Dahlén J \& Söderquist P. 2015. Svarthakad buskskvätta - en ny fas av etableringen i Sverige. Anser 54: 28-30.

Dahlén J \& Söderquist P. 2016. Svarthakad buskskvätta - bästa året hittills för arten $i$ Sverige. Available at http://birdlife.se/ svarthakad-buskskvatta-basta-aret-hittills-for-arten-i-sverige/

Dybbro T. 1976. De danske ynglefugles udbredelse. Dansk Ornitologisk Forening, København.

Eichstädt W, Scheller W, Selin D, Starke W \& Stegemann K-D. 2006. Atlas der Brutvögel in Mecklenburg-Vorpommern. Steffen Verlag, Friedland.

Gedeon K, Gruneberg C, Mitschke A \& Sudfeldt C. 2014. Atlas Deutscher Brutvogelarten. Stiftung Vogelmonitoring Deutschland und Dachverband Deutscher Avifaunisten, Munster.

Glutz von Blotzheim UN \& Bauer KM. 1988. Handbuch der Vögel Mitteleuropas. AULA-Verlag, Wiesbaden.

Haas F, Barbet-Massin M, Green M, Jiguet F \& Lindström Å. 2014. 
Species turnover in the Swedish bird fauna 1850-2009 and a forecast for 2050. Ornis Svecica 24: 106-128. https://doi.org/10.34080/ os.v24.19602

Hellström M \& Waern M. 2005. Svarthakad buskskvätta, ras och åldersbestämning vår och sommar. Vår Fågelvärld 64(2): 36-43.

Hellström M \& Waern M. 2011. Field identification and ageing of Siberian Stonechats in spring and summer. British Birds 104: 236-254.

Huntley B, Green RE, Collingham YC \& Willis SG. 2007. A climatic atlas of European breeding birds. Lynx Edicions, Barcelona.

SOVON Vogelonderzoek Nederland. 2002. Atlas van de Nederlandse broedvogels 1998-2000: verspreiding, aantalen, verandering. Nederlandse Fauna 5. Nationaal Natuurhistorisch Museum Naturalis, KNNV Uitgeverij \& European Invertebrate Survey-Nederland, Leiden.

Klinteroth L. 2015. Ny stjärna på himlen. Vår Fågelvärld 74(4): 14-18. Knief W, Berndt RK, Hälterlein B, Jeromin K, Kieckbusch JJ \& Koop B. 2010. Die Brutvögel Schleswig- Holsteins. Ministerium fur Landwirtschaft, Umwelt und ländliche Räume des Landes Schleswig-Holstein.

Nyegaard T, Meltofte H, Tofft J \& Grell MB. 2014. Truede og själdne ynglefugle i Danmark 1998-2012. Dansk Ornitologisk Forenings Tidsskrift 108: 1-144. Available at https://www.dof.dk/images/ projekter/truedeynglefugle/dokumenter/DOFT_1_2014.pdf
Rudebeck G. 1962. Våra Svenska fåglar i färg. AB Svensk Litteratur, Stockholm.

Shimmings P \& Öjen IJ. 2015. Bestandsestimater for norske hekkefugler. NOF-rapport 2015-2. Available at http://www.birdlife.no/innhold/ bilder/2016/03/17/3739/nof_rapport_bestandsestimater.pdf

SOF Sveriges Ornitologiska Förening. 1965. Förteckning över Sveriges fäglar. 5:e uppl. Svensk Natur, Stockholm.

SOF Sveriges Ornitologiska Förening. 2002. Sveriges fåglar. 3:e uppl. Stockholm.

Størkersen $\varnothing R$. 1994. Svartstrupe Saxicola torquata. In: Gjershaug JO, Thingstad PG, Eldöj S \& Byrkjeland S (eds). Norsk Fugleatlas. Norsk Ornitologisk Forening, Klæbu. Available at http://www. birdlife.no/fuglekunnskap/fugleatlas/index.php?taxon_id=9799

Svensson L. 1992. Identification Guide to European Passerines. Stockholm.

Svensson S, Svensson M \& Tjernberg M. 1999. Svensk fågelatlas. Vår Fågelvärld, supplement 31. Sveriges Ornitologiska förening, Stockholm.

Åhlund I. 2007. Svarthakad buskskvätta i Bohuslän. Fåglar i Bohuslän 2: 9-18.

Wernersson A. 2017. En ny bekantskap på de halländska kusthedarna. Fåglar i Halland 2016.

Wirdheim A \& Carlén T. 1986. Fågelstråk - Hallands fågelliv i ord och bild. Spektra, Halmstad.

\section{English Summary}

From a historic point of view, the European Stonechat Saxicola rubicola has been a rare bird in Sweden and as late as in 1961, only 15 records had been reported. 25 breedings were confirmed in the country between 2000 and 2015. There were eleven individuals observed in the Swedish West Coast during the early 1980s. During the succeeding decades, until 2014, only a few individuals were annually reported on the West Coast (SOF 1965, SOF 2002, Dahlén \& Söderquist 2015, 2016). The aim of this paper is to document the process of the expansion during the breeding season (March-August) on the West Coast (Göteborg/Bohuslän, Halland) during the last ten year period (2009-2018). Special emphasis is put on the breeding seasons 2017 and 2018, as various degrees of systematic surveying were performed.

Published historical information regarding the West Coast, but also Scandinavia as a whole, has been studied to get an overview of the process of expansion. In addition to the 2017-2018 censuses, the data regarding the West Coast is to a large extent built on spontaneous reports received by the database Artportalen.

With the aim of reflecting the real number of adult individuals, the findings are divided into four catego- ries: temporary observation, permanent song territory, possible breeding and confirmed breeding. A temporary observation defined as birds that have occurred only a couple of days on a site, while a song territory is considered as permanent if a male has spent at least ten days on the location and if the major part of that time has been after 15 April. The classification of breeding status follows the criteria for probable (categories 5-10) and confirmed (categories 11-20) breeding outlined in Svensk Fågelatlas (Svensson et al. 1999).

An attempt to a crude classification of the biotopes were made for all of the 83 territories 2014-2018. In approximately half of the cases, the age of the males could be determined with help of detailed photos. The age determination was made by the author and is based on general moult criteria (Svensson 1992, Hellström \& Waern 2005, Hellström \& Waern 2011). Arrival and fledgling dates have also been registered during the censusing.

The number of adult individuals as well as breedings during the ten-year period are presented in Figure 1, while the geographical distribution of the breedings in 2017 and 2018 is shown in Figure 2. Sites and status 
for all of the 83 territories $2014-2018$ are presented in Table 1. Examples of density and size of the territories are given in Figure 3. The arrival date for 13 investigated territories 2017 occurred on average on 23 March, while the corresponding date for 18 territories 2018 was 5 April, see Figure 4. The birds appeared in pairs already at the first observation in 21 of the territories (68\%). 42 out of the $83(51 \%)$ territory males 2014-2018 could be age determined. 32 of these $(76 \%)$ were one year old males $(2 \mathrm{CY})$. The biotope distribution and examples of the appearances of the territories are shown in Figures 5-7. The fledgling date for 68 clutches 2014-2018 was distributed over a long period of time, from May to August, see Figure 8. Out of the 77 breedings 20142018 , breeding data were examined in 32 cases. Second clutches were confirmed in ten of these $(31 \%)$. The date when the ten confirmed first clutches left the nests occurred in average on 30 May, while the corresponding date of the second clutches occurred on 17 July. There are no confident indications that third clutches existed.

The European Stonechat's expansion on the West Coast and in other parts of the country should be seen in the context of Danish immigration in combination with a large-scale advance via the German Schleswig-Holstein area (Knief et al. 2010, Gedeon et al. 2014, Nyegaard et al. 2014). An ongoing colour-ringing study in Scania suggests that relatively few birds return the subsequent season (Dahlén \& Söderquist 2015, 2016). This could indicate that the current increase is mainly due to over production in the core areas further south. The proportion of $2 \mathrm{CY}$ males in the West Coast was high compared to southern populations, thus indicating an influx from the south to our breeding areas. In Norway, where the European Stonechat is mainly a res- ident bird, large-scale re-immigration, probably from Great Britain, has followed subsequent to decimation during cold winters (Shimmings \& Öjen 2015).

The arrival to the West Coast occurs approximately two weeks later compared to southern populations. Migrating populations in Central Europe regularly produce two clutches, while resident birds often produce three and sometimes even four clutches (Cramp 1988). The material from the West Coast shows that only $31 \%$ produced two clutches and no indications of more clutches exist. Although it is reasonable to assume that some second clutches have been missed, the result is still considerably lower than for southern populations.

The European Stonechat belongs to the species whose range expansions are commonly associated with climate change, and the Swedish population is expected to increase according to predictions of the future bird fauna (Huntley et al. 2007, Haas et al. 2014). There are hardly any doubts that the climate has a big impact since populations in other locations have shown large variations with significant decreases after cold winters (Glutz von Blotzheim \& Bauer 1988, Shimmings \& Öjen 2015). This is furthermore shown by the late arrival to the West Coast during the spring of 2018, following unusually cold weather and low temperatures in the Central Europe. This might have influenced the territory establishment and resulted in fewer pairs than would otherwise have been the case. It is hence reasonable to expect temporary setbacks for the continued expansion of the European Stonechat. Due to warmer climate, plenty of appropriate biotopes and high probability of reproduction, the conditions are however good for a quick recovery and continued expansion in southern Sweden.

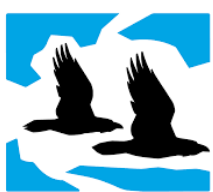

BirdLife Sverige

Ornis Svecica (ISSN 2003-2633) is an open access, peer-reviewed scientific journal published in English and Swedish by BirdLife Sweden. It covers all aspects of ornithology, and welcomes contributions from scientists as well as non-professional ornithologists. Accepted articles are published at no charge to the authors. Read papers or make a submission at os.birdlife.se.

Ornis Svecica (ISSN 2003-2633) är en fritt tillgänglig granskad vetenskaplig tidskrift som ges ut på svenska och engelska av BirdLife Sverige. Den täcker ornitologins alla områden och välkomnar bidrag från såväl forskare som icke-professionella ornitologer. Accepterade uppsatser publiceras utan kostnad för författarna. Läs uppsatser eller skicka in ditt bidrag på os.birdlife.se. 